Научная статья

УДК 82.0:34

DOI 10.18101/2686-7095-2021-4-15-21

\title{
ПРОБЛЕМАТИКА ПРАВ ЧЕЛОВЕКА \\ В РОМАНЕ Ф. М. ДОСТОЕВСКОГО «ПОДРОСТОК»
}

\author{
(C) Чимитова Ирина Зоригтоевна \\ кандидат социологических наук, \\ Бурятская государственная сельскохозяйственная академия им. В. Р. Филиппова \\ Россия, 670024, г. Улан-Удэ, ул. Пушкина, 8 \\ rindaol@mail.ru.
}

\begin{abstract}
Аннотация. Заметное место в романе «Подросток» занимает проблема прав человека. Юридическая коллизия связана с правовым статусом главного героя, Аркадия, имеющего как «юридического отца» - бывшего дворового Макара Долгорукого, так и родного - помещика Версилова. Положение матери Аркадия дворовой девушки Софьи обусловило статус ее как незаконной супруги, а детей, Аркадия и Лизы, как незаконнорожденных, ущемленных в правах и достоинстве. О зависимом положении Софьи говорит факт ее выкупа Версиловым у Макара, вероятность для нее остаться на старости лет без средств, то, что муж на полгода забыл ее за границей, а также его попытки жениться на других женщинах. Достоевский глубоко осмыслил правовое положение рожденных вне брака, особенно детей дворовых, в условиях пережитков крепостного права в России второй половины XIX в., призвав читателей к установлению правовой и социальной справедливости, равноправия, а также к добросердечию и милосердию.

Ключевые слова: права человека, достоинство, правовой статус, незаконнорожденный, крепостное право, дворовый, муж, жена, дети, герой, роман.
\end{abstract}

\section{Для цитирования}

Чимитова И. З. Проблематика прав человека в романе Ф. М. Достоевского «Подросток» // Вестник Бурятского государственного университета. Филология. 2021. Вып. 4. C. 15-21.

Предметом широкого общественного интереса проблема прав человека и гражданина в нашей стране стала благодаря трудам А. Н. Радищева, других общественных деятелей, литераторов и ученых XVIII-XIX вв., выступавших против крепостного права. В 1860-е гг. в России полагали, что его отмена «знаменует начало эпохи классового мира, что реформа устраняет причины сословного антагонизма». В отличие от Западной Европы, где «разделение нации на враждующие классы представлялось явлением закономерным», на отечественной почве такое казалось «преходящим, легко устранимым...» [9, с. 79]. Однако позже Достоевский убедился в актуальности вопросов, связанных, в частности, с проблемой прав человека, отраженной в романе «Подросток» ${ }^{1}$

Юридическая коллизия и соответствующая терминология возникают уже в самом начале произведения: главный герой Аркадий Долгорукий, от лица кото-

${ }^{1}$ Не случайно специалисты, излагая историю отечественной правовой теории, включают в анализ и фигуру Достоевского [4, с. 52]. 
рого ведется повествование, представляется читателю как сын «юридического отца» Макара Долгорукого, бывшего садовника, дворового господ Версиловых, «законнорожденный, хотя... в высшей степени незаконный сын», т. к. в действительности его отцом является помещик Версилов [3, с. 7-8]. Что касается матери Аркадия Софьи, то юридически она жена Долгорукого и одновременно фактическая супруга Версилова, его бывшая дворовая.

Брак дворовых, как было принято в системе крепостного права, был заключен с разрешения господ, в роли которых выступила по-соседски присматривавшая за имением Версиловых помещица Татьяна Павловна Пруткова. Говоря о пожелании отца Софьи, завещавшего Макару вырастить девушку и жениться на ней, повествователь отмечает неправоспособность завещателя как крепостного. Как известно, у крепостных были попраны права на свободу, достоинство личности, неприкосновенность частной жизни, свободу передвижения и места жительства и ряд других прав и свобод.

Размышляя с долей иронии над неясной для него причиной, побудившей Софью полюбить Версилова, Аркадий подчеркивает их разнородность: «...может быть, она полюбила до смерти... фасон его платья..., тот романс, который он спел.., полюбила нечто никогда не виданное и не слыханное (а он был очень красив собою), и уж заодно полюбила, прямо до изнеможения, всего его, с фасонами и романсами. Я слышал, что с дворовыми девушками это иногда случалось во времена крепостного права... Я это понимаю, и подлец тот, который объяснит это одним только крепостным правом и “приниженностью”! Итак, мог же... этот молодой человек иметь в себе столько самой прямой и обольстительной силы, чтобы привлечь такое чистое до сих пор существо, и, главное, такое совершенно разнородное с собою существо, совершенно из другого мира и из другой земли» $[3$, с. 16$]$.

Социальная дифференциация явно ощущалась в первой половине 1870-х гг., когда создавался роман «Подросток». Сталкивались представители различных позиций. Так, защитники устаревших феодальных прав, дворянских привилегий препятствовали расширению прав других сословий, требовали закрыть представителям последних доступ к высшему образованию, за исключением обучения простым техническим навыкам. Романом, главный герой которого - выходец из «промежуточных слоев», его автор полемизировал с ретроградами [10, с. 28].

У писателя были для этого все основания, в том числе опыт осмысления широкого круга вопросов социального и культурного развития страны. Известный юрист и философ конца XIX - начала XX в. П. И. Новгородцев, ставивший во главу угла своей теории права характерную для национальной культуры категорию «любовь», считал вершиной отечественной правовой мысли и выражением русского народного характера творчество Достоевского. «Именно от Ф. М. Достоевского через Вл. Соловьева к Б. Н. Чичерину, Л. И. Петражицкому, Н. М. Коркунову, Б. Ф. Кистяковскому, С. А. Муромцеву, М. М. Ковалевскому, Г. Ф. Шершеневичу идет основная нить развития русской философии права...», комментирует взгляды Новгородцева В. С. Дробышевский [5, с. 56-57].

Идейная борьба продолжилась и в конце 19-го столетия, в том числе в сфере юридической науки. Высказывались противоположные взгляды. Наряду с такими трудами, как работа А. Г. Мартенсона «Что такое так называемое право и наука о 
нем: правоведение или юриспруденция» (1890), в которой право сближалось со справедливостью, нравственностью, равенством, были и другие, в которых «особенностью социально-экономической основы русской правовой мысли... являлось сохранение многочисленных пережитков крепостничества» [11, с. 64].

Гениальность созданных писателем образов общепризнанна, и центральный герой анализируемого романа не исключение. К нему в полной мере относится высказывание Д. И. Заславского: «В «Подростке» много сильных, ярких мест, много правдивых, жизненных образов. С обычным психологическим мастерством Достоевский проникает в душу своих героев, расследует их затаенные помыслы» [7, с. 64]. Причем важны нюансы и тонкости, характерыне для изображаемого времени.

Так, с увлечением Версилова либерализмом связано окрашенное комизмом описание начала связи родителей Аркадия, когда будущий отец был вдовцом с двумя детьми, а будущая мать - законной женой Макара, с которым обвенчалась за полгода до того. Отец вспоминает, что они с Софьей «прятались по углам, поджидая друг друга на лестницах..., и “тиран помещик” трепетал последней поломойки, несмотря на все свое крепостное право» [3, с. 15].

Без тени неловкости он, относящий себя к лучшей тысяче россиян, говорит о торге с Макаром, предметом которого были люди: «Я тогда предложил ему три тысячи рублей... мне вообразилось, что он меня боится, то есть моего крепостного права... если он не захочет... трех тысяч, вольной (ему и жене, разумеется) и вояжа на все четыре стороны (без жены, разумеется)... Он на другой же день согласился на вояж... не забыв ни одной из предложенных мною наград» [3, c. 132-133].

Барина неприятно поразило, что бывший дворовый осмелился потребовать с него обещанное судом, что говорит об уме и предусмотрительности Макара, понявшего суть натуры своего господина, его легкомыслие, эгоцентризм, неспособность думать о других и финансово обеспечившего формальную супругу: «если бы... мать пережила г. Версилова, то осталась бы... без гроша на старости лет, когда б не эти три тысячи Макара..., давно уже удвоенные процентами и которые он оставил ей все целиком... Он предугадал Версилова даже в то еще время» [3, с. 134].

Будучи бесконечно выше мужа по нравственному уровню, Софья, так и оставшаяся полуграмотной, рабски служит ему как смиренная, безответная, трепещущая жертва. Муж воспринял модные в сороковые годы идеи, «то есть признал, что мужик - это тоже человек» и женщина должна иметь равные права с мужчиной $[8$, с. 590]. Однако на деле его жена ущемлена в правах, и сын «хочет прочного союза» между Версиловым и матерью, желает «вернуть навсегда» его ей $[8$, с. 593].

За нарушения моральных норм Версилов был наказан лишь дважды, когда за бесчестное поведение был отлучен от света и когда жених Катерины Ахмаковой Бьоринг посчитал ниже своего достоинства вызвать его на дуэль. Обычно же все сходило ему с рук, о чем Аркадий говорит: «Ничего ему не будет ... никогда ему ничего не бывает; никогда ничего с ним не случится и не может случиться, это такой человек!» [3, с. 334]. 
Аркадий не сразу осознал свое положение. Этому поспособствовало его пребывание в пансионе Тушара, в котором он подвергался избиениям, унижению, инстинктивно, пытаясь защититься, прислуживал Тушару, не понимая причины своих страданий - низкого правового статуса: «Я старался из всех сил угодить и нисколько не оскорблялся, потому что ничего еще я этого не понимал...; был так еще тогда глуп, что не мог понять, как я им всем неровня. Правда, товарищи много мне и тогда уже объяснили, школа была хорошая. Тушар кончил тем, что полюбил более пинать меня коленком сзади, чем бить по лицу; ...нетнет, а в месяц раз наверно побьет..., чтоб не забывался» [3, с. 122]. Соученики, подражая директору, тоже изощрялись в издевательствах.

Так, из-за жестокости окружающих Аркадию уже в детстве пришлось осознать изъяны своего статуса, усвоить, что он, несмотря на свои способности и образованность, безродный, побочный сын и брат, неровня законным детям Версилова, что у него нет семьи, фамилии, привыкнуть, что путают два его отчества, снести унизительный визит к сводному брату и рукоприкладство со стороны Бьоринга, приказавшего лакеям схватить и удерживать юношу на глазах Ахмаковой, в которую тот влюблен. Даже отец использует доверенную сыном тайну для клеветы на Ахмакову. Не принимавший участия в воспитании детей и неродной им Макар посчитал себя вправе почти требовать, чтобы их не выводили из низших сословий.

В разговоре с приятелем Ефимом Зверевым о возможности дуэли с князем Сергеем Сокольским с целью отомстить за обиженного Версилова юноша снова слышит, что дуэль может быть только с ровней. На его возражение, что он «тоже джентльмен по развитию», «имеет права» и «ровня», а князь, напротив, «неровня» ему, Ефим парирует:

«- Нет, ты маленький.

- Как маленький?

- Так маленький; мы оба маленькие, а он большой» [3, с. 144].

Похожая коллизия возникает, когда Аркадий, узнав о беременности Лизы от упомянутого князя, сомневается: имеет ли он как брат право вызвать того на дуэль. «А я вот и не знаю, как тут надо поступить честному человеку!.. Почему? Потому что мы - не дворяне, он - князь..., он нас, честных-то людей, и слушать не станет. Мы даже и не братья с тобой, а незаконнорожденные какие-то, без фамилии, дети дворового, а князья разве женятся на дворовых?», — говорит он ей [3, с. 302].

Из-за низкого статуса главного героя публично опозорили в подпольном игорном клубе, обыскав и назвав вором, и, хотя потом выяснилась несправедливость этих подозрений, никто не извинился перед ним. Даже опекавшая семью Пруткова обижает юношу, говоря, что у него лакейская душа. Она считает, что он должен быть благодарен Версилову за то, что его не отдали в сапожники. «Нет, ты не ценишь, что он тебя до университета довел и что через него ты права получил», — заявляет она.

Отделавшись от мальчика лишь платой за обучение, Версилов лишил его нормального семейного воспитания, любви и заботы родителей, сестры. Пострадали его человеческое достоинство, право на личную и семейную тайну и другие 
права и свободы. Версилов не может понять, что сыну нужно было не дворянство, а он сам как отец.

Он бесстыдно уверяет юношу, что он вполне законный сын Макара, что, говоря о незаконнорожденности, Аркадий клевещет и разоблачает материнскую тайну (что она до сих пор не Версилова), т. к. формально замужем за Макаром, умалчивая о собственной неблаговидной роли.

Себе же он дал право жить десятилетиями в незаконном союзе с Софьей и покидать ее, когда захочет «разжениться», состоя в фактическом браке, пытаться жениться на других дамах. Он не сдержал своего «дворянского слова» узаконить отношения с Софьей после кончины Макара. Вместо этого Версилов, следуя своей двойственной натуре, сделал предложение Ахмаковой.

Главный герой разоблачает безмерный эгоцентризм Версилова: «Живет лишь один Версилов, все остальное кругом него и все с ним связанное прозябает под тем непременным условием, чтобы иметь честь питать его своими силами, своими живыми соками» [3, с. 129].

Несмотря на то, что в молодости Версилов осуждал «родовые права», «деревни», несмотря на гуманные речи, которые он «говорил хорошо», для него непреодолим водораздел между ним, барином, дворянином, и Софьей, бывшей дворовой, ее детьми, «простыми сердцами», «народом», «этой средой», которых он чаще всего называет словом «они» и которых считает противоположностью себе, одному из «прекрасных людей». «Версилов не мог выкорчевать из себя высокомерного, помещичьи-аристократического отношения к людям», - отмечает В. Кирпотин [6, с. 591]. Не являются исключением даже самые близкие и родные, члены его семьи.

Не случайно из всех положительных черт Макара Версилов превыше всего ценит почтительность, которая, по его убеждению, «необходима для высшего равенства, мало того, без которой... не достигнешь и первенства» [3, с. 135], а суть этой почтительности состоит, как он считает, в покорном принятии всего предназначенного ему свыше, даже приниженного положения.

Ложность правового статуса молодого человека парадоксально подчеркивается громкостью фамилии, которую он вынужден носить и которая провоцирует неделикатных и неумных людей на обременительные и надоевшие ему расспросы: «...редко кто мог столько вызлиться на свою фамилью, как я, в продолжение всей моей жизни... Каждый-то раз, как я вступал куда-либо в школу или встречался с лицами, которым, по возрасту моему, был обязан отчетом, одним словом, каждый-то учителишка, гувернер, инспектор, поп - все кто угодно, спрося мою фамилью и услыхав, что я Долгорукий, непременно находили для чего-то нужным прибавить:

- Князь Долгорукий?

И каждый-то раз я обязан был всем этим праздным людям объяснять:

- Нет, просто Долгорукий.

Это просто стало сводить меня наконец с ума» [3, с. 9-10].

Зависимое положение может приводить к аберрации сознания, что показано на примере Макара, ужасно любившего и уважавшего «свою фамилью “Долгорукий”. Разумеется, это - смешная глупость. Всего глупее то, что ему нравилась его фамилья именно потому, что есть князья Долгорукие. Странное понятие, со- 
вершенно вверх ногами!» [3, с. 18]. Так думает юноша, чувствующий себя самостоятельной личностью с адекватным чувством собственного достоинства.

Аркадий презирает «ноющее по себе сиротство», утверждая, что «ничего нет омерзительнее роли, когда сироты, незаконнорожденные, все эти выброшенные...; к которым я нисколько вот-таки не имею жалости, вдруг торжественно воздвигаются перед публикой и начинают жалобно, но наставительно завывать: “Вот, дескать, как поступали с нами!” Я бы сек этих сирот. Никто-то не поймет из этой гнусной казенщины, что в десять раз ему благороднее смолчать, а не выть и не удостоивать жаловаться. А коли начал удостоивать, то так тебе, сыну любви, и надо» [3, с. 77]. По мнению Е. И. Семенова, утверждая это, герой «опирается на глубоко обоснованные человеческие права (в этом-то и смысл мотива полемики с “ноющими по себе сиротами”) и требования целого класса таких, как он» $[10$, c. 75$]$.

В противовес приниженности герой грезит о свободе, силе, могуществе, «идее» стать как Ротшильд, но если у Раскольникова это вылилось в преступление, то Аркадий не способен на злодеяние: оно претит его «человеческой натуре», «его болению» за страдания людей, его желанию «облегчить их положение». Тем самым писатель стремится утвердить мысль, что «идея» может и не помешать добру, когда добрая натура берет верх над нею или когда она попадает в добрые руки [6, с. 68-69].

Как видим, писатель поднял целый комплекс проблем, касающихся многих болевых точек жизни российского общества, его прошлого и даже будущего, бытия и сознания своих современников. Говоря о «Подростке», М. С. Гус отмечает: это роман «о том, что таится в душе иного задумавшегося подростка из случайного семейства в «смутное время» 70-х гг. XIX в. в России» [2, с. 458].

Таким образом, Ф. М. Достоевский глубоко осмыслил проблему прав человека в условиях сохранившихся пережитков крепостного права, показал всю сложность правового положения рожденных вне брака детей, особенно детей дворовых. Он подверг резкой критике правовую и социальную несправедливость в российском обществе описываемого периода, призывая читателей к гуманности, добросердечию, милосердию, справедливости, установлению всеобщего равноправия.

\section{Литература}

1. Владимирский-Буданов М. Ф. Обзор истории русского права. Москва: Территория будущего, 2005. 800 с. Текст: непосредственный.

2. Гус М. С. Идеи и образы Достоевского. 2-е изд., доп. Москва: Художественная литература, 1971. 592 с. Текст: непосредственный.

3. Достоевский Ф. М. Подросток. Москва: Гос. изд-во худ. лит-ры, 1961. С. 7-582. Текст: непосредственный.

4. Дробышевский В. С. Право и культура: Социально-философский аспект теории российского права. Чита: Изд-во Забайкал. ин-та предпринимательства Сиб. ун-та потребит. кооперации, 1997. 192 с. Текст: непосредственный.

5. Дробышевский В. С. Социология права. Вып. 1. Теория, история и проблемы ценностно-культурологического анализа. Чита: Изд-во Забайкал. ин-та предпринимательства Сиб. ун-та потребит. кооперации, 1997. 69 с. Текст: непосредственный.

6. Ермакова М. Я. Романы Достоевского и творческие искания в русской литературе XX в. Горький: Волго-Вятское кн. изд-во, 1973. 320 с. Текст: непосредственный. 
7. Заславский Д. И. Ф. М. Достоевский: Критико-биографический очерк. Москва: Гос. изд-во худ. лит-ры, 1956. 80 с. Текст: непосредственный.

8. Кирпотин В. Роман Достоевского «Подросток» // Достоевский Ф. М. Подросток. Москва: Гос. изд-во худ. лит-ры, 1961. С. 583-609. Текст: непосредственный.

9. Розенблюм Л. М. Творческие дневники Достоевского. Москва: Наука, 1981. 368 с. Текст: непосредственный.

10. Семенов Е. И. Роман Достоевского «Подросток» (проблематика и жанр). Ленинград: Наука, 1979. 168 с. Текст: непосредственный.

11. Сонин В. В., Федоров В. П. Правопонимание в дореволюционной немарксистской юридической мысли России // Государственный строй и политико-правовые идеи России второй половины XIX столетия: межвузовский сборник научных трудов. Воронеж: Изд-во Воронеж. ун-та, 1987. С. 60-68.

Статья поступила в редакцию 19.11.2021; одобрена после рецензирования 29.11.2021; принята к публикации 10.12.2021.

\title{
PROBLEMS OF HUMAN RIGHTS IN FYODOR DOSTOEVSKY'S NOVEL "THE ADOLESCENT"
}

\author{
Irina Z. Chimitova \\ Dr. Sci. (Sociol.), Senior Lecturer, \\ Filippov Buryat State Agricultural Academy \\ 8 Pushkina St., Ulan-Ude 670034, Russia \\ rindaol@mail.ru
}

Abstract. The problem of human rights figures prominently in the novel "The Adolescent". The conflict of laws was associated with the legal status of the protagonist Arkady, who had both "a legal father" — the formed predial serf Makar Dolgorukiy and a birth father - the landowner Versilov. The position of Arkady's mother Sofya as a serf girl determined her status as illegal wife, and the status of their children, Arkady and Sofya, as illegitimate children, disadvantaged in their rights and dignity. Sofya's redemption from Makar by Versilov, risk to be left destitute at her age, the fact that the husband forgot her in foreign country for half-year, and his attempts to marry other ladies testify to her dependent status. Dostoevsky reflected deeply on the legal status of illegitimate children, especially children of serfs, in Russia of the second half of the $19^{\text {th }}$ century, when there were still the remnants of serfdom, and called readers to establishment of legal and social justice, equality of rights, benignity and mercy.

Keywords: human rights, dignity, legal status, illegitimate child, serfdom, serf, husband, wife, children, the character, novel.

\section{For citation}

Chimitova I. Z. Problems of Human Rights in Fyodor Dostoevsky's Novel "The Adolescent". Bulletin of Buryat State University. Philology. 2021; 4: 15-21 (In Russ.).

The article was submitted 19.11.2021; approved after reviewing 29.11.2021; accepted for publication 10.12.2021. 